\title{
WOOD ASH AS AN EFFECTIVE RAW MATERIAL FOR CONCRETE BLOCKS
}

\author{
Prabagar Subramaniam $^{1}$, Kalya Subasinghe ${ }^{2}$, W. R. Keerthi Fonseka ${ }^{3}$

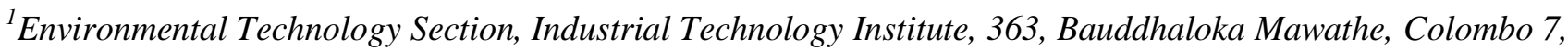 \\ Sri Lanka \\ ${ }^{2}$ Environmental Technology Section, Industrial Technology Institute, 363, Bauddhaloka Mawathe, Colombo 7, \\ Sri Lanka \\ ${ }^{3}$ Environmental Technology Section, Industrial Technology Institute, 363, Bauddhaloka Mawathe, Colombo 7, \\ Sri Lanka
}

\begin{abstract}
Utilization of wood ash as a partial substitution for cement is one of the promising method to increase the strength and thermal insulation for cement blocks. The present study focused to use wood ash as a partial replacement for cement material during sand cement block manufacturing. The concrete mixtures have been mixed with 10\%, 15\% 20\% and $25 \%$ of wood ash as a partial replacement for cement with sand and tested for compressive strength, water absorption and heat release. Higher compressive strength was observed in the samples of $15 \%$ containing wood ash replacement material. All the samples other than $25 \%$ of wood ash replacement were shown lower water absorption and highest was found in 15\% wood ash content. Slower heat release was observed in the samples of $15 \%$ and $20 \%$ of wood ash replacement after 21 days of curing time. Addition of $15 \%$ wood ash for the manufacturing of concrete blocks was developed and these blocks meet standard limits.
\end{abstract}

Keywords: wood ash, water absorption, compressive strength, cement block.

\section{INTRODUCTION}

The concrete blocks have been used in many developing countries including Sri Lanka over a long period of time. In building construction, different types of bricks and blocks are used in Sri Lanka. The factors related to structural performances are crucial, when using masonry blocks in constructing walls and buildings. Many studies have been carried out to identify highly available, low cost innovative material to use in construction industry as a solution to meet the ever increasing demand for raw material. Among the new materials introduced to the market, light-weight materials are becoming much popular nowadays because of its easy handling and low dead loads (1).

Concrete which is being widely used in the construction industry has unlimited opportunities for innovative applications design and construction techniques. Factors such as strength, workability and durability of the ordinary concrete are continuously being modified to make it more suitable for a specified construction purpose. This has become more realistic due to the advancement of technology. Several studies have been carried out to identify substitutes for fine aggregates $(2,3)$ and for cement $(3)$ in manufacturing concrete products that would enhance the properties while reducing the cost. Rice husk ash (4), coconut shell and wood ash (5) could be used as a partial replacement of cement. Ash is the inorganic incombustible part of fuel left after complete combustion, and contains the bulk of the mineral fraction of the original biomass. Currently the biomass ash is used in several manufacturing processes such as cement clinker production, production of bricks, binding material for soil stabilization and also as a raw material for the production of synthetic aggregates, fertilizers or liming agents (6).

Wood ash is generated as a by-product of combustion in wood fired power plants, paper mills, and wood burning factories. Since wood is a potential source of energy and environmentally benign friendly material, there will be increased usage of wood in energy production in the future. As a result the quantity of ash generated will also increased and concurrently raising the issues of disposal. Incorporation of wood ash as a partial replacement of cement material in blended cement and concrete will be beneficial from both the environmental and economic point of views. This will give a solution to the waste management problem while minimizing the consumption of energy intensive hydraulic cement. Currently, wood ashes are frequently used as a soil supplement to improve the alkalinity of soil for agriculture applications and also as a filler material in the construction of flexible pavements for roads and highways (7).

Several studies have analyzed the suitability of wood ash as a partial cement replacement material in the production of structural grade concrete and self compacting concrete for applications in building construction $(8,9,10,11)$. Wood fly ash consists of particles which are highly irregular in shape with a highly porous surface (12). Physical, chemical and micro-structural properties of wood ash could significantly affect the pozzolanic and hydraulic reactivity. Therefore the properties of wood ash obtained from different sources should be characterized before being incorporated as cement 
replacement material in production of concrete. A study was evaluated the physical properties of wood ashes from five different sources which concluded that wood ash samples have varying values of unit weight that range from 162 $\mathrm{kg} / \mathrm{m}^{3}$ to a maximum of $1376 \mathrm{~kg} / \mathrm{m}^{3}$ (13). The specific gravity of wood ash ranged between 2.26 and 2.60. Low unit weight and specific gravity of wood ashes indicate the possibility of the reduction in the unit weight of concrete material by the partial substitution of cement with wood ash. The amount of ash generated after combustion could vary with the type of biofuel (14). The chemical compounds present in the wood and woody biomass ashes have been studied (15) and greater percentages of $\mathrm{CaO}$ have reported in most types of wood including in Birch bark, Pine bark, Spruce bark.

In Sri Lanka, sand cement blocks are widely used in the construction industry, as they could cemented rapidly. These blocks are mainly constructed using cement and fine aggregates with a standard composition. This study analyzed the compressive strength, water absorption ratios and heat holding capacity of sand cement blocks manufactured with wood ash through laboratory experiments.

\section{MATERIALS AND METHODS}

\subsection{Collection of Wood Ash}

Wood ash was collected from Tasma International Multiservice (Pvt) Ltd, Sri Lanka. The chemical composition of the ash was determined the elements such as Total Potassium, Phosphorous, Nitrogen, Magnesium, Calcium and Silicon were determined.

\subsection{Manufacturing of Blocks}

Wood ash was sieved through a $75 \mu \mathrm{m}$ sieve to remove the coarse particles present in the ash, before being used for block manufacturing. A total of five sets of cement blocks were prepared for this study; S1, S2, S3, S4 and S5. First set of blocks ( $\mathrm{S} 1)$ which is the control set was prepared by mixing the cement and sand in 1: 6 proportions used in local block manufacturing process. S2, S3, S4 and S5 blocks were prepared by mixing wood ash as a partial replacement of cement in the following percentages; $10 \%, 15 \%, 20 \%$, $25 \%$ respectively and carried out the same process done for S1 block preparation. Assessing the blocks with different percentages of wood ash will allow us to determine the optimum percentage of ash that could be used without any significant negative deviations from standard cement block (S1).

\subsection{Structural Properties of Cement Blocks}

\subsubsection{Compressive Strength}

The compressive strength was investigated in the laboratory by using crushing machine. Three samples were tested for each set of blocks and were tested at the age of 7,14 and 21days. The average compressive strength was determined by averaging the corresponding compressive strength values. The strength characteristics of S2, S3, S4 and S5 blocks were compared with the $\mathrm{S} 1$ cement block.

\subsubsection{Water Absorption}

Water absorption was carried out in all five sets of cement blocks. Sample blocks from each set including the control (S1) were tested for water absorption assuming that it is a representative of the unit population. The sample blocks were oven dried for 24 hours at a temperature of $100-105^{\circ} \mathrm{C}$ until the mass became constant and measured the dry weights of the blocks (W1). Then the same blocks were immersed in water for 24 hours and measured the wet weight of each block (W2). Percentage of water absorption of individual sample blocks was determined using the following equation.

Percentage of water Absorption $=[(\mathrm{W} 2-\mathrm{W} 1) / \mathrm{W} 1] \times 100$

Where, W1 = Oven dry weight of the specimen, W2 = wet weights of the specimen

\subsubsection{Heat Release}

Heat holding test was carried out by using Thermal Imaging Scanner. Sample block from each set were kept in an oven at $100-105^{\circ} \mathrm{C}$, for the time period of 24 hours and measured the emissivity within 2 hours. Then the heat holding and emitting pattern of all sample blocks including test specimens and control specimen were computed.

\section{RESULTS}

\subsection{Chemical Composition of Wood Ash}

The total percentage of magnesium and calcium were found to be 0.9 and 5.7 respectively. The amount of Silicon was less than $32.5 \mathrm{mg} / \mathrm{kg}$ which is the minimum detection limit of the equipment. The percentage of potassium, phosphorus and nitrogen were 4.9, 2.4 and 0.03 respectively.

\subsection{Compressive strength}

Compressive strengths of cement blocks measured at different curing times are given in Table 1. It shows that the compressive strength value for all sample blocks increase with the curing time (Figure 1). The results of One Way ANOVA test showed that there is a significant difference among sample blocks in terms of compressive strength at all stages of curing ( 7 days of curing: $p<0.001,14$ days of curing: $p<0.001,21$ days of curing: $p=0.003)$. The compressive strength of the S5 was significantly lower than the control block (S1) at all curing stages indicating its incompatibility as a building material (Tukey HSD, p < $0.05)$. The optimum compressive strength is given at $15 \%$ wood ash replacement after 21 days of curing. 
Table 1: The average compressive strength of blocks

\begin{tabular}{|l|l|l|l|}
\hline \multirow{2}{*}{ Wood Ash content $\mathbf{( \% )}$} & \multicolumn{3}{|l|}{ Strength/ $\left(\mathbf{N} / \mathbf{m m}^{2)}\right.$} \\
\cline { 2 - 4 } & 7 Days & 14 Days & 21 Days \\
\hline 0 & 1.9592 & 2.4338 & 3.1033 \\
\hline 10 & 2.2939 & 2.2477 & 2.6142 \\
\hline 15 & 2.1917 & 2.5074 & 3.6631 \\
\hline 20 & 1.9736 & 2.6200 & 2.8046 \\
\hline 25 & 1.1974 & 1.1974 & 1.4052 \\
\hline
\end{tabular}

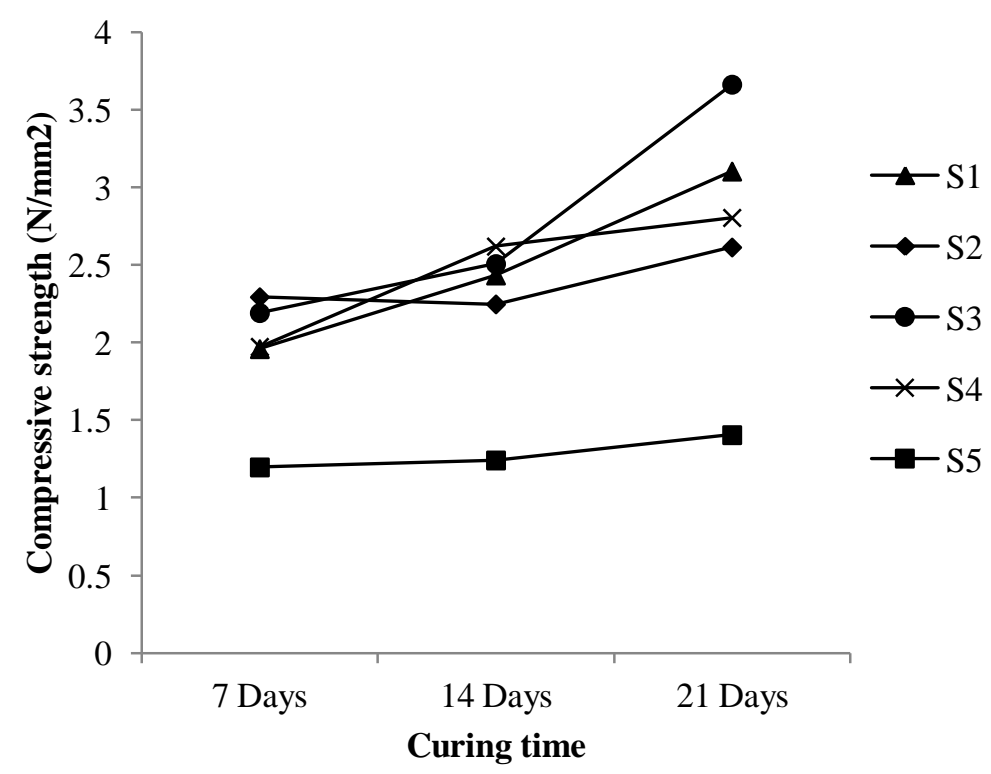

Fig.1. Compressive strength of blocks with aging

\subsection{Water Absorption}

The variation in water absorption with percentage of wood ash at 7, 14 and 21 days are shown in Figure 2 . According to the results, percentage of water absorption of all sample blocks except S5 are lower than the control block after 21 days of curing period and the lowest absorption level was detected in S3 which is correspondent to the $15 \%$ wood ash replacement.

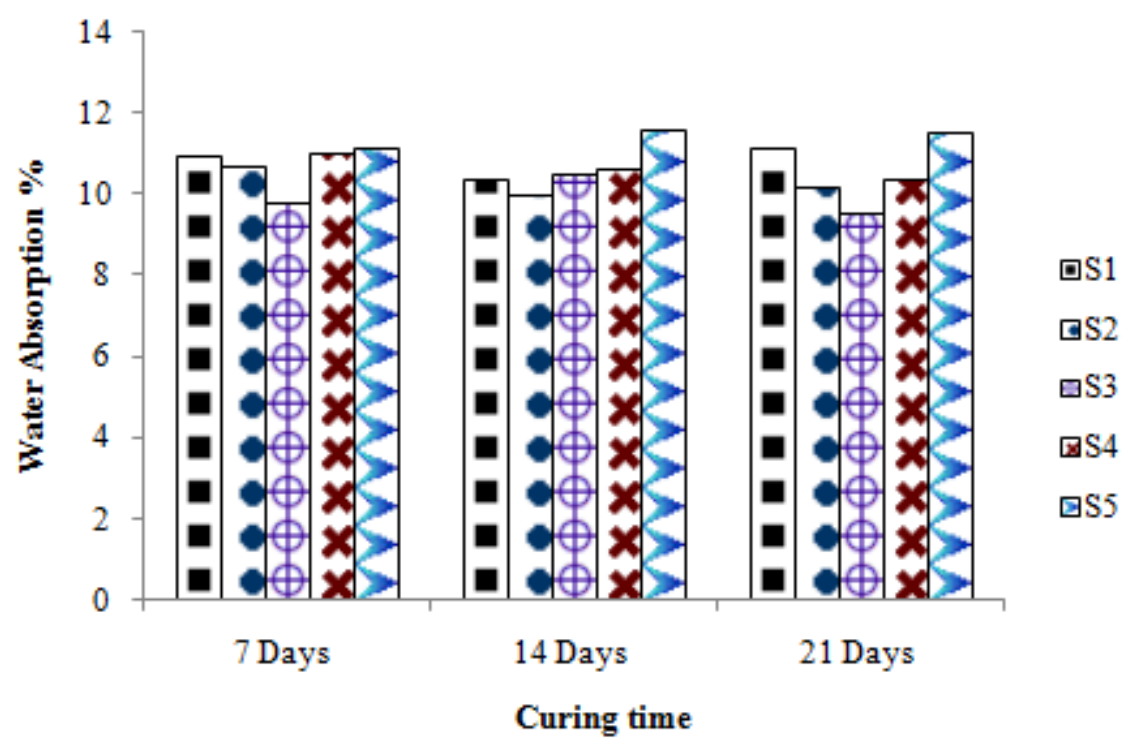

Fig.2. water absorption (\%) with age 


\subsection{Heat Release}

The variation of heat release with percentage of wood ash at 7, 14 and 21 days are shown in Figure 3. The increase of surface temperature from 7 day of curing time to 14 days indicates reduction of heat release with the curing time. However further curing shows an increase trend of heat release in all sets of sample blocks (Figure 3a and 3b). The lower surface temperature difference in S3 and S4 after 21 days indicates the slow release of heat by both sample blocks (Figure 3c).

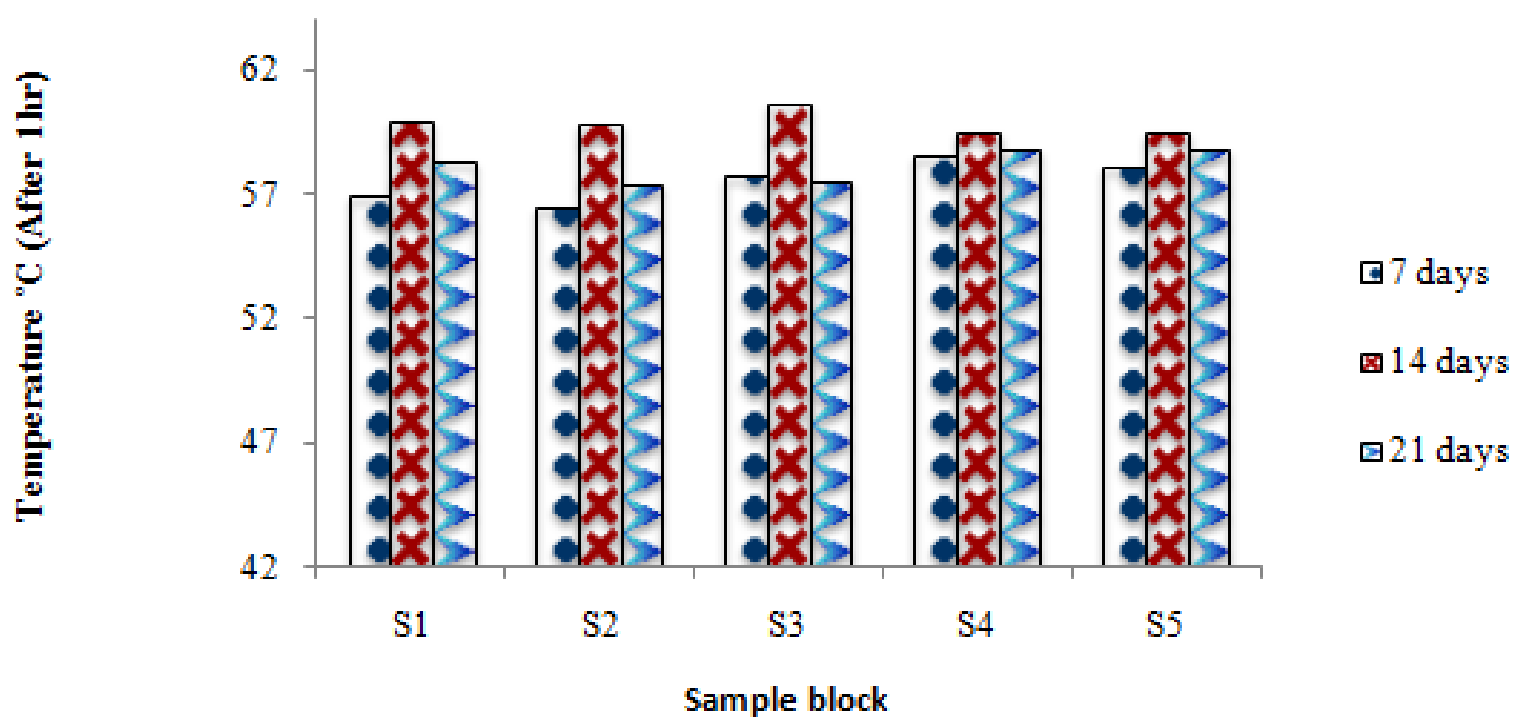

Fig.: 3a. Surface temperature after 1 hour

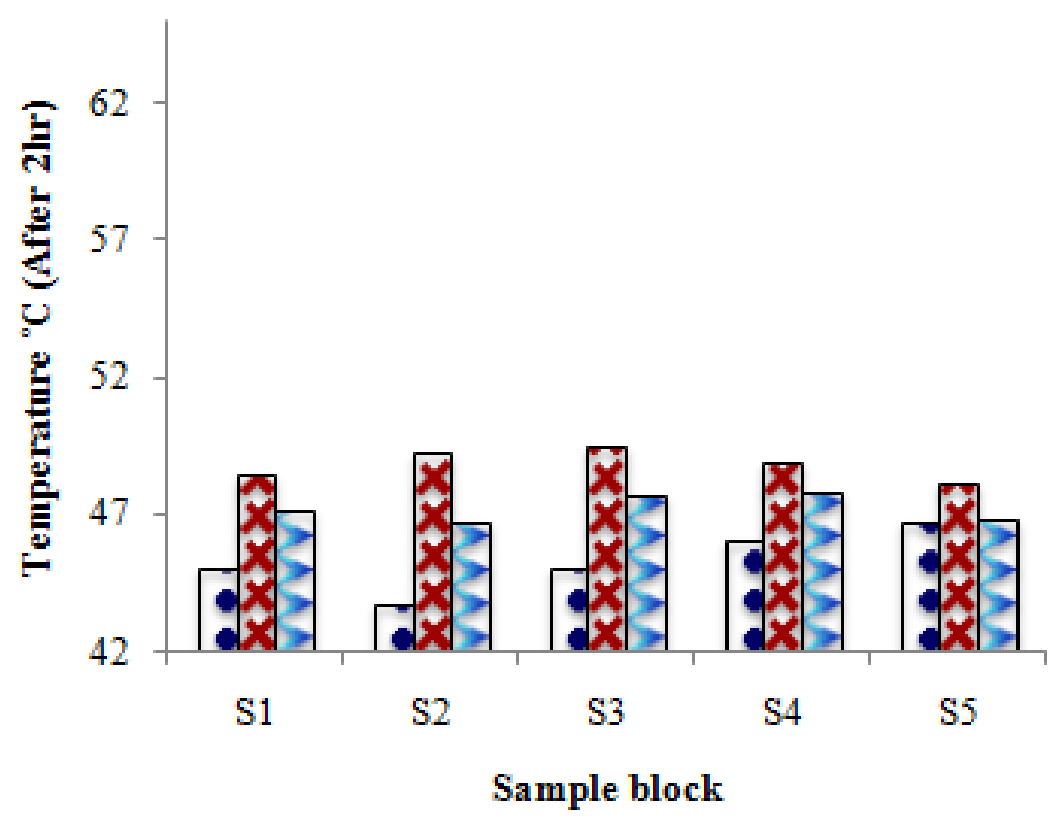

a 7 days

⿴囗1 14 days

$\boxminus 21$ days

Fig: 3b Surface temperature after 2 hours 


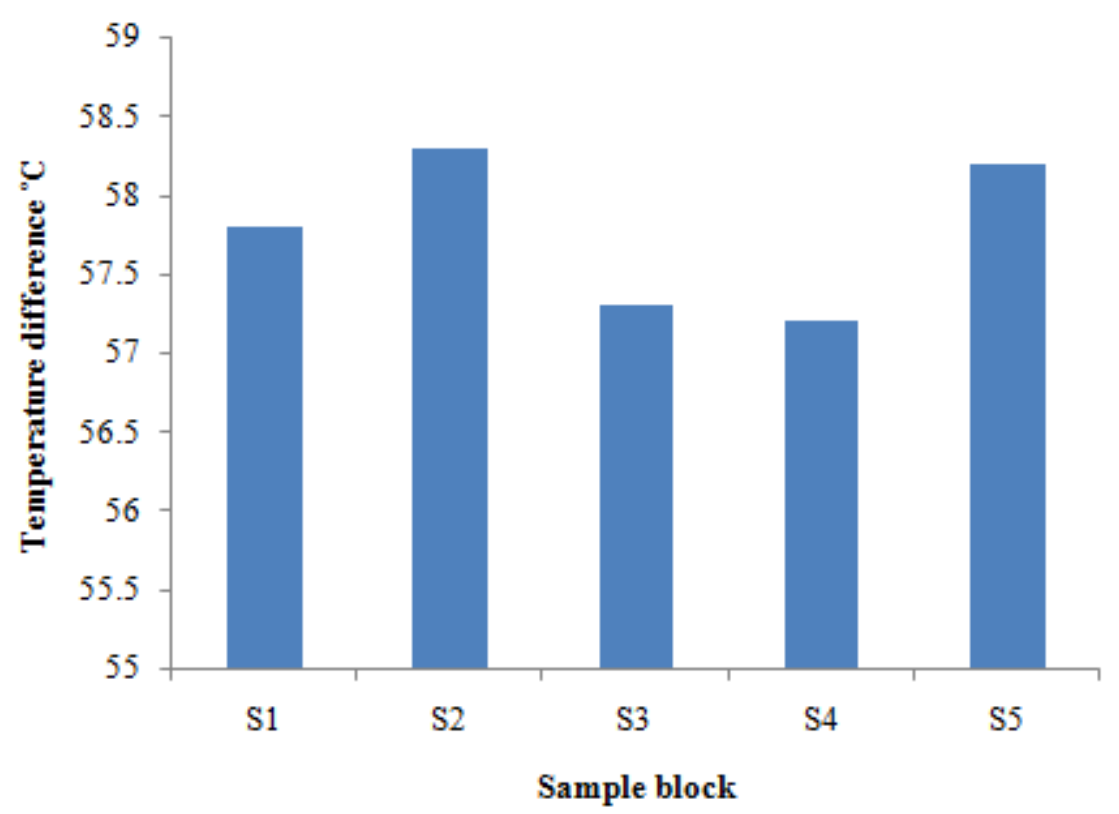

Fig: 3c. Temperature difference between initial and after 2 hours at 21 day of curing period

\section{DISCUSSION}

Compressive strength of the cement blocks made with partial replacement of wood ash $(\leq 20 \%)$ did not show a significant difference from the control block (Tukey HSD; $p$ $<0.05)$. Cement block with a $15 \%$ wood ash replacement (S3) showed the highest compressive strength which is a $9 \%$ increase compared to control block (S1). It complies with the minimum standard value of $2.8 \mathrm{~N} / \mathrm{mm}^{2}$ according to BS 6073: Part 2: 1981. This higher compressive strength may be due to the pozzolanic reaction of wood ash. The $\mathrm{pH}$ value increases with the hydration of cement. Presence of potassium, magnesium and calcium in the wood ash increases the $\mathrm{pH}$ value of hydrated cement mixture and enhance the pozzolanic activity. Increased $\mathrm{pH}$ levels encourage the formation of hydrous silica. This compound reacts with $\mathrm{Ca}^{2+}$ ions and produce insoluble compounds which are secondary cementations products. Large surface area associated with the ash particles also could be a factor which enhances the comprehensive strength of the wood ash based sand cement blocks as explained in a study conducted to analyze the contribution of rice husk ash on concrete (16). Sharp decrease in the compressive strength at more than $20 \%$ of wood ash replacement levels was observed. The decline of strength with the increase of proportions of ash was reported in many reports $(17,18)$.

The durability of the concrete is largely affected by absorption of water (19). The concrete blocks with lower permeability show a high resistance to deterioration. Decreasing water permeability is due to an extensive pore refinement caused by the ash in the matrix and in the interface layer (20). The results show that the water absorption level is lower than the control block after 21 days of curing period and the lowest absorption was detected from the sample block with $15 \%$ of wood ash incorporation.
The heat from the sample block with $15 \%$ wood ash (S3) is released at a slower rate than all other sample blocks including the control block. This property is essential to maintain the thermal comfortableness in indoor and outdoor settings.

\section{CONCLUSION}

The wood ash has the potential ability to replace the cement partially in cement block manufacturing industry. According to the results, the optimum percentage of wood ash that can replace cement is $15 \%$ and it provides a block with a high compressive strength. Water absorption capacity is obtained at $15 \%$ of wood ash replacement after 21 days of curing period. Wood ash is a valuable addition due to its slow rate of heat release and $15 \%$ replacement showed slower heat release. The Blocks can be modified with $15 \%$ of wood ash together with other cement materials.

\section{ACKNOWLEDGEMENTS}

The authors wish to express their gratitude to the Tasma International Multiservice (Pvt) Ltd, Sri Lanka for its financial assistance.

\section{REFERENCES}

[1] Gunasekaran K, Kumar PS, Lakshmipathy M. 2011. Mechanical and bond properties of coconut shell concrete. Construction and building materials 25(1):92- 98.

[2] Aggarwal P, Aggarwal Y, Gupta SM. 2007. Effect of bottom ash as replacement of fine Aggregates in concrete. Asian journal of civil engineering (building and housing) 8(1):49-62. 
[3] Madhavi TP, Sampathkumar V, Gunasekaran P. 2013. Partial replacement of cement and fine aggregate by Using fly ash and glass aggregate. International Journal of Research in Engineering and Technology.351-355.

[4] Antiohos S.K, Papadakis V.G, Tsimas S. 2014. Rice husk ash (RHA) effectiveness in cement and concrete as a function of reactive silica and fineness. Cement and Concrete Research. (61-62) 20-27.

[5] Udoeyo FF, Inyang H, Young DT, Oparadu EE. 2006. Potential of wood waste ash as an additive in concrete. Journal of Materials in Civil Engineering 18(4):605-11.

[6] van Eijk RJ, Obernberger I, Supancic K. 2012. Options for increased utilization of ash from biomass combustion and co-firing. KEMA: Arnhem, The Netherlands.

[7] Etiegni, L., and A. G. Campbell. 1991. Physical and chemical characteristics of wood ash. Bioresource Technology, (37), 173-178.

[8] Elinwa AU, Ejeh SP, Mamuda AM. 2008. Assessing of the fresh concrete properties of self-compacting concrete containing sawdust ash. Construction and building materials. 22:1178-82.

[9] Elinwa AU, Ejeh SP. 2004. Effects of incorporation of sawdust incineration fly ash in cement pastes and mortars. Journal of Asian Architecture and Building Engineering 3(1):1-7.

[10] Elinwa AU, Mahmood YA. 2002. Ash from timber waste as cement replacement material. Cement and Concrete Composites 24:219-22.

[11] Abdullahi M. 2006. Characteristics of wood ash/OPC concrete. Leonardo Electronic Journal of Practices and Technologies 8:9-16.

[12] Wang S, Baxter L, Fonseca F. 2008. Biomass fly ash in concrete: SEM, EDX and ESEM analysis. Fuel 87:372-9.

[13] Naik TR, Kraus RN, Siddique R. 2003. Use of Wood Ash in Cement-based Materials. Center for ByProducts Utilization (CBU-2003-19;REP-513) Available at http://uwm.edu/Dept/CBU/report

[14] Khan, A.A, de Jong, W, Jansens, P.J, Spliethoff. 2009. Biomass combustion in fluidized bed boilers: Potential problems and remedies. Fuel Processing Technology, (90): 21-50.

[15] Vassilev SV, Baxter D, Andersen LK, Vassileva CG. 2013. An overview of the composition and application of biomass ash. Part 1. Phase-mineral and chemical composition and classification. Fuel 105:40-76.

[16] Naji Givi AN, Rashid SA, Aziz FNA, Salleh MAM. 2010. Contribution of Rice Husk Ash to the Properties of Mortar and Concrete: A Review. Journal of American Science 6(3):157-165.

[17] Raheem AA, Adenuga OA. 2013. Wood Ash from Bread Bakery as Partial Replacement for Cement in Concrete. International Journal of Sustainable Construction Engineering and Technology 4(1):7581.
[18] Rajput J, Yadav RK, Chandak R. 2013. The Effect of Rice Husk Ash used as Supplementary Cementing Material on Strength of Mortar. International Journal of Engineering Research and Applications 3(3):133-136.

[19] Ithuralde G. 1992. Permeability: The Owner's Viewpoint. In: Mailer Y. ed. High Performance Concrete From Material to Structure. London: 276294.

[20] Rodrigues, CS, Ghavami K, Stroeven Piet. 2006. Porosity and water permeability of rice husk ashblended cement composites reinforced with bamboo pulp. Journal of Materials Science 41(21): 69256937.

BS 6073-2: 1981 Precast concrete masonry units. Method for specifying precast masonry units

BS 5628-1: 2005 Code of practice for the use of masonry. Structural use of unreinforced masonry 